\title{
Potencial alelopático do extrato aquoso de aveia preta e azevém na germinação e crescimento inicial do capim-sudão
}

\author{
Allelopathic potential of the aqueous extract of black oats and ryegrass in the \\ germination and initial growth of the sudan grass
}

\author{
Márcio Cavalli ${ }^{l}$; Michele da Silva Santos ${ }^{2}$; Mara Karinne Lopes Veriato Barros*3; Helder Morais Mendes Barros ${ }^{4}$; \\ Karina Xavier Leite Barosi ${ }^{5}$
}

\begin{abstract}
Resumo: A pecuária brasileira é sustentada em pastagens, pela sua praticidade e economia. Entre as espécies anuais de inverno mais utilizadas para pastejo na Região Sul do Brasil estão à aveia preta e o azevém, isolados ou em misturas, em função da facilidade na aquisição de sementes e em relação ao ciclo de produção das espécies. Entre as espécies de verão o Capim-Sudão vem se destacando, usado como alternativa para diminuir as dificuldades encontradas em obter forragem na época seca do ano, por facilidade de cultivo, rusticidade, tolerância à seca, rapidez no estabelecimento e crescimento, e facilidade de manejo sob corte e ou pelo pastejo direto. O presente estudo objetivou-se verificar o potencial alelopático do extrato aquoso em diferentes concentrações da aveia preta e azevém sobre a germinação e crescimento inicial do capim-Sudão. O experimento foi realizado na safra 2013/14, na Universidade do Oeste de Santa Catarina (UNOESC), campus de São José do Cedro, Santa Catarina, em estufa. Para o delineamento estatístico foi utilizado o método DBC (delineamento em blocos casualizados) fatorial, com três tratamentos e cinco doses com quatro repetições. Pela porcentagem de germinação, comprimento de plantas e comprimento de raízes comparadas nas dosagens do extrato aquoso houve efeito alelopático na germinação do Capim-Sudão. E pelos índices de massa fresca e seca da parte aérea e radicular, e também visto no índice de velocidade de germinação que a partir das doses de $50 \%$ da solução aquosa dos extratos da aveia e azevém e da mistura aveia + azevém que ocorreu efeito alelopático sobre a germinação do Capim-Sudão.
\end{abstract}

Palavras-chave: Sorghum sudanense; Forragem; Alimentação animal.

\begin{abstract}
The Brazilian livestock farming is sustained in pastures, due to its practicality and economy. Among the annual winter species most used for grazing in southern Brazil are black oats and ryegrass, isolated or in mixtures, due to the ease of seed acquisition and the production cycle of the species. Among the summer species, Sudan grass has been used as an alternative to reduce the difficulties encountered in obtaining fodder in the dry season of the year, for ease of cultivation, rusticity, drought tolerance, fast establishment and growth, and ease of cultivation. Handling under cut and / or by direct grazing. The objective of the present study was to verify the allelopathic potential of the aqueous extract in different concentrations of black oats and ryegrass on the germination and initial growth of the Sudan grass. The experiment was carried out in the 2013/14 harvest, at the University of the West of Santa Catarina (UNOESC), in the São José do Cedro campus, in the greenhouse. For the statistical design, the DBC (randomized complete block design) method was used, with three treatments and five doses with four replicates. By the percentage of germination, plant length and root length compared in the dosages of the aqueous extract, there was an allelopathic effect on the germination of the Sudan Grass. And by the fresh and dry mass index of the shoot and root, and also seen in the rate of germination that from the doses of $50 \%$ of the aqueous solution of the extracts of oats and ryegrass and the oat + ryegrass mixture that occurred allelopathic effect On the germination of Sudan Grass.
\end{abstract}

Key words: Sorghum sudanense; Forage; Animal feed.

\footnotetext{
*Autor para correspondência

Recebido para publicação em 15/08/2016; aprovado em 20/12/2016

${ }^{1}$ Eng. Agrônomo, Universidade Oeste de Santa Catarina, Campus de São José do Cedro, São José do Cedro, Santa Catarina, Brasil, E-mail: marcio.cavalli@yahoo.com.br;

${ }^{2}$ Mestre em Eng. Agrônomo, Professor a, Unipampa - Universidade Federal do Pampa. Itaqui, Rio Grande do Sul, Brasil. E-mail: michelef1v@ hotmail.com;

${ }^{3}$ Mestranda em Recursos Naturais, CTRN/UFCG, Campina Grande, Paraíba, Brasil .Email:karinnelv@yahoo.com.br;

${ }^{4}$ Doutor em Eng. Agrícola, CTRN/UFCG, Campina Grande, Paraíba, Brasil. E-mail: hmmbbr@yahoo.com.br;

${ }^{5}$ Advogada-Faculdade de Ciências Sociais Aplicadas ,. E-mail: karina_xl@yahoo.com.br
} 


\section{INTRODUÇÃO}

A pecuária brasileira é sustentada em pastagens, pela sua praticidade e economia, porém, os resultados econômicos obtidos pela maioria dos pecuaristas estão muito abaixo das possibilidades produtivas (VITOR et al., 2009). A baixa produtividade das pastagens é uma das principais causas da baixa lucratividade e competitividade do sistema de produção de bovinos a pasto Essa característica é ainda mais evidente na Região Sul do Brasil devido às baixas temperaturas, geadas e pouca luminosidade no outono e inverno (CECATO et al., 1998).

Entre as espécies anuais de inverno mais utilizadas para pastejo na Região Sul do Brasil estão à aveia preta (Avena strigosa schreb) e o azevém (Lolium multiflorium Lam), isolados ou em misturas, basicamente em função da facilidade na aquisição de sementes e das particularidades em relação ao ciclo de produção das espécies (ROSO; RESTLE, 2000). Entre as espécies de verão o Capim-Sudão (Sorghum sudanense) vem se destacando, onde, vem sendo utilizado como alternativa para diminuir as dificuldades encontradas em se obter forragem na época seca do ano, por facilidade de cultivo, rusticidade, tolerância à seca, rapidez no estabelecimento e crescimento, bem como por sua facilidade de manejo sob corte e ou pelo pastejo direto (ZAGO, 1997).

De acordo com Silveira (2010) o evento da germinação e crescimento inicial da planta pode ser afetado por inúmeras interposições. Estas podem ser de natureza abiótica ou biótica. Quando de natureza abiótica, a interferência se dá pela influência de fatores ambientais como luz, água, temperatura, vento, $\mathrm{pH}$ e disponibilidade de nutrientes, ou ainda pela interação entre ambos. Quando de natureza biótica, a interferência pode ser por meio de substâncias químicas tóxicas, liberadas no meio por outras plantas ou pela decomposição do resíduo. A interferência abiótica pode ser vista como ação promotora da competição entre plantas (FERREIRA; BORGHETTI, 2004). Esse fenômeno onde a planta pode interferir direta ou indiretamente, no desempenho de outras plantas ou em microorganismos sobre outra planta, mediante produção de compostos químicos (aleloquímicos) que são liberados no ambiente (RICE, 1984). Esses compostos químicos são encontrados distribuídos em concentrações variadas nas diferentes partes da planta, e durante o seu ciclo de vida. As substâncias alelopáticas liberadas por uma planta poderão afetar o crescimento, o desenvolvimento normal e até mesmo inibir a germinação das sementes de outras espécies vegetais (SILVA, 1978).

Em algumas ocasiões acontecem o insucesso no estabelecimento de pastagens no campo por problemas de alelopatia entre as espécies cultivas em sucessão nas estações de inverno/verão. Este transtorno acontece principalmente pela falta de informações disponíveis e conclusivas a respeito dos obstáculos envolvidos neste processo. Desta forma para se adotar práticas de manejo que auxiliem no manuseio das espécies de pastagens e destituir os custos de produção são necessários que se conduzam pesquisas para avaliar os potenciais efeitos alelopáticos entre espécies que são utilizadas na Região Sul do Brasil, que sofre pela falta de alimentação constante para seu rebanho nas diferentes épocas do ano.

Efeitos inibitórios da germinação e do desenvolvimento da plântula, atribuídos à alelopatia têm sido obtidos por vários autores. Almeida (1993), analisando os efeitos dos extratos aquosos da Brachiaria decumbens, Brachiaria humidicola e Brachiairia brizantha cv Marandu sobre as leguminosas centrosema (Centrosema pubescens); calopogônio (Calopogonium mucunoides); macrotiloma (Macrotiloma axilares cv. Guatá) e estilosantes (Stylosanthes spp. guianensis), observou reduções na germinação das sementes das leguminosas, exceto as do Guatá, e na produção de matéria seca da parte aérea e das raízes da centrosema, do macrotiloma e do estilosantes.

Efeitos alelopáticos de extratos voláteis de óleos essenciais de canela (Cinnamomum zeylanicum Breyn.), alecrim-pimenta (Lippia sidoides Cham.), capim citronela (Cymbopogum citratus (DC) Stapf.), alfavaca-cravo (Ocimum gratissimum L.) e jaborandi (Pilocarpus microphyllus Stapf. ex.Wardleworth) evidenciaram potencialidades alelopáticas na germinação e comprimento das raízes de plântulas de alface, efeitos que variaram de acordo com a concentração do óleo. O extrato volátil de óleo de jaborandi estimula o crescimento da radícula e não provoca inibição da germinação de sementes de alface ( $L$. sativa), caracterizando-se como de efeito alelopático benéfico (ALVES et al., 2004).

Trabalhando com extratos aquosos preparados a partir de folhas e colmos de três gramíneas de estação fria, festuca alta (Festuca arundinacea Sch.), azevém anual (Lolium multiflorum) e cevadilha (Critesion purillum) em diferentes concentrações, Smith e Martim (1994) verificaram que para concentrações dos tecidos das três gramíneas doadoras acima de $7,0 \mathrm{~g} / \mathrm{l}$, houve uma completa inibição do crescimento das plântulas de alfafa.

Souza et al. (1993), estudaram em condições de casade-vegetação a possível ocorrência de efeito alelopático de 18 espécies de plantas daninhas sobre o crescimento inicial de Eucalyptus grandis e observaram alterações importantes no desenvolvimento das mudas, tais como desaceleração no crescimento em altura, diâmetro do caule, produção de matéria seca e variações no teor de clorofila. Entre as espécies testadas, B. decumbens provocou os efeitos mais drásticos, principalmente no desenvolvimento da parte aérea, reduzindo em $97,74 \%$ e $62,81 \%$ o aumento da matéria seca de caules e folhas e das raízes das plantas de eucalipto, respectivamente.

Abbado (1995) avaliou os possíveis efeitos alelopáticos dos extratos das leguminosas Guandu (Cajanus cajan), Crotalária júncea (Crotalaria juncea L.), Feijão-dePorco (Canavalia ensiformis), Lablab (Lablab purpureus L. cv. Rongai) e Mucuna Preta (Mucuna aterrima) sobre a germinação e o crescimento das plantas de Capim Brachiária (Brachiaria decumbens). Em laboratório, observou que a $C$. juncea e o L. purpureus prejudicaram a germinação, o comprimento da radícula e a produção de matéria seca da braquiária. Entretanto, em casa de vegetação houve efeito alelopático dos extratos das leguminosas apenas na germinação e no desenvolvimento radicular. $\mathrm{O}$ presente estudo objetivou-se verificar o potencial alelopático do extrato aquoso em diferentes concentrações da aveia preta e azevém sobre a germinação e crescimento inicial do capimSudão em São José do Cedro, Santa Catarina (SC).

\section{MATERIAL E MÉTODOS}

O experimento foi realizado na safra 2013/14, no Campus da Unoesc, em estufa, na linha esquina derrubada, zona rural do município de São José do Cedro - SC, com 
latitude de $26^{\circ} 28^{\prime} 40^{\prime \prime} \mathrm{S}$ e longitude de $53^{\circ} 30$ '32' W e altitude média de 720 m (GOOGLE EARTH, 2008). O clima é Cfa Clima subtopical; temperatura média no mês mais frio inferior a $18^{\circ} \mathrm{C}$ (mesotérmico) e temperatura média no mês mais quente acima de $22^{\circ} \mathrm{C}$, com verões quentes, geadas pouco frequentes e tendência de concentração das chuvas nos meses de verão, contudo sem estação seca definida, de acordo com a classificação de Köppen (SANTA CATARINA, 2007).

$\mathrm{O}$ experimento foi realizado no método DBC (delineamento em blocos casualizados) com esquema fatorial $3 \times 5 \times 4$, onde foi utilizado o extrato aquoso de aveia preta, azevém e aveia preta + azevém com 5 (cinco) doses diferentes de concentração do extrato $(0 \%, 25 \%, 50 \%, 75 \%$, e $100 \%)$, totalizando 60 (sessenta) unidades experimentais.

$\mathrm{O}$ extrato foi preparado primeiramente utilizando aveia preta, o segundo utilizando o azevém, e o terceiro foi realizada uma mistura de aveia preta + azevém.

Para preparar o extrato aquoso de aveia preta ou o extrato de aquoso de azevém foi utilizado $1 \mathrm{~kg}$ (aveia preta ou de azevém) em 2L de álcool, envolvendo os recipientes de aveia preta ou o azevém junto ao álcool com papel alumínio para manter a solução em regime de escuridão por $48 \mathrm{~h}$, posteriormente foram abertos os recipientes e mantidos abertos por $24 \mathrm{~h}$ para a evaporação do álcool. Para o preparo do extrato aquoso da mistura da aveia preta + azevém foi utilizado $500 \mathrm{~g}$ de aveia preta $+500 \mathrm{~g}$ de azevém em $2 \mathrm{~L}$ de álcool, seguindo o mesmo procedimento citado anteriormente, conforme metodologia descrita por Nery (2013).

A Aveia e o Azevém utilizados para o preparo do extrato foram coletados em uma propriedade na linha São João do Município de Flor da Serra do Sul, Paraná.

Na semeadura do Capim-Sudão foi usado $25 \mathrm{~kg} / \mathrm{ha}$ de sementes puras e viáveis (RAMON, 2012). E foi semeado em vasos com área de $0,047 \mathrm{~m}^{2}$, onde foi semeado $0,118 \mathrm{~g} / \mathrm{vaso}$, que corresponde a 10 sementes de Capim-Sudão em cada vaso. E junto na semeadura foi feito a aplicação das dosagens de $0 \%, 25 \%, 50 \%, 75 \%$, e $100 \%$ do extrato aquoso, correspondendo as dosagens de $0 \%$ que contém $100 \mathrm{ml}$ de apenas água, $25 \%$ contém $25 \mathrm{ml}$ de extrato e $75 \mathrm{ml}$ de água, $50 \%$ contém $50 \mathrm{ml}$ de extrato e $50 \mathrm{ml}$ de água, $75 \%$ contém $75 \mathrm{ml}$ de extrato e $25 \mathrm{ml}$ de água, e $100 \%$ contém $100 \mathrm{ml}$ de extrato puro.

Conforme Fonseca e Martuscello (2010), a produção de massa da Aveia e Azevém em situações de bom manejo podem atingir $10000 \mathrm{~kg}$.ha de massa seca. Então para o trabalho foi usado 8 ton/ha de massa de aveia e Azevém como média de produção base. Onde $100 \mathrm{ml}$ do extrato é equivalente a 8 ton/ha de massa verde, $75 \mathrm{ml}$ equivale a 6 ton/ha, $50 \mathrm{ml}$ equivale a $4 \mathrm{ton} / \mathrm{ha}$, e $25 \mathrm{ml}$ equivale a 2 ton/ha de massa verde.

O material do solo utilizado foi classificado como tipo 2 pra a recomendação de P, conforme CQFS, SC e RS (2004), coletada na camada superficial $(0$ a $15 \mathrm{~cm})$ de uma área localizada no campus da Unoesc.

A análise do solo da área experimental apresenta os valores de pH em H2O: 5,3; Índice de SMP: 5,7; Al Trocável: 0,1 Cmolc/dm ${ }^{3}$; Teor de matéria orgânica: $4,1 \mathrm{~g} / \mathrm{dm}^{3} ; \mathrm{K}: 71$ mg/dm³ P: 4,7 mg/dm³; CTC: 10,04 Cmolc/dm³; Saturação de bases: 38,68 \%; Saturação de Alumínio: 2,1 \%; Argila: 46 $\%$.

Para gramíneas forrageiras de estação quente o $\mathrm{pH}$ recomendado é 5,5, e conforme índice SMP, a necessidade de calcário de $2800 \mathrm{~kg} / \mathrm{ha}$. Onde foi usado 13,16g de calcário.
O Capim-Sudão produz cerca de $15000 \mathrm{Kg}$ de massa seca por hectare e por ano (RAMON, 2012). Com isso foi necessário adubação de $410 \mathrm{~kg}$ de N/ha, $170 \mathrm{~kg}$ de P2O5/ha e de $200 \mathrm{~kg}$ de K2O/ha, conforme Manual CQFS, SC e RS, 2004. Logo, o adubo utilizado foi o $09-20-15$ e com isso, foi aplicado $4 \mathrm{~g} /$ vaso de adubo.

A irrigação foi feita manualmente todos os dias da realização do experimento, sendo que no plantio foi feito as aplicações das dosagens do extrato e no restante dos dias foi irrigado de 100 a $150 \mathrm{ml}$ de água/vaso, avaliando a umidade do solo existente nos vasos, onde por acaso o solo estivesse muito seco aplicava $150 \mathrm{ml}$ de água, e se o solo estivesse úmido aplicava $100 \mathrm{ml}$ de agua.

Foi avaliada a porcentagem final de germinação (plântulas normais, plântulas anormais e sementes mortas) do Capim-Sudão. Foi realizada ainda a medição com régua graduada do desenvolvimento radicular medindo-se o comprimento da raiz principal, bem como o comprimento das plantas no $15^{\circ}$ dia e de avaliação quando foi feito a coleta de dados.

Ao final da produção no $15^{\circ}$ dia, coletou-se as fitomassas para determinação da fitomassa fresca e seca da parte aérea (FFPA -FSPA), fitomassa fresca e seca da raiz (FFR- FSR). A fitomassa seca total (FST) foi determinada pelo somatório da FSPA e FSR. Depois de coletadas, tanto a parte aérea como as raízes foram acondicionadas em sacos de papel, devidamente identificados, e levados à estufa com circulação forçada de ar quente a $65^{\circ} \mathrm{C}$, até peso constante durante 14 horas. Em seguida o material vegetal foi pesado em balança eletrônica com precisão para 0,001 g (BENINCASA, 2003).

As variáveis analisadas foi porcentagem de germinação $(\% \mathrm{G})$, onde foi feito diariamente a contagem de plantas germinadas desde o plantio até a colheita do CapimSudão no $15^{\circ}$ dia após o plantio. Essa variável foi analisada determinando o número de sementes germinadas (NSG) em relação ao número de sementes semeadas (NSS) após 15 dias após o plantio (Equação 1).

$$
\% G=(\mathrm{NSG} / \mathrm{NSS}) \times 100
$$

Outra variável analisada foi o índice de velocidade de emergência (IVE), onde foi avaliada a velocidade de emergência nos diferentes tipos de extratos e dosagens, e analisados quais tratamentos apresentaram melhor desempenho. Essa variável foi analisada observando o dia de emergência e o número de plântulas emergidas.

$$
\operatorname{IVE}_{\text {(plântulas dia-1) }}=\left(\Sigma \mathrm{NPE}_{1} / \mathrm{N}_{1}\right)+\left(\Sigma \mathrm{NPE}_{2} / \mathrm{N}_{2}\right)+\ldots+\left(\Sigma N P E_{\mathrm{n}} / \mathrm{N}_{\mathrm{n}}\right) \text { Eq. } 2
$$

Em que: $\Sigma \mathrm{NPE}_{1}, \Sigma \mathrm{NPE}_{2}, \ldots \Sigma \mathrm{NPE}_{\mathrm{n}}$ : Representam os números de plântulas emergidas, computadas na primeira, segunda e última contagem, respectivamente; $\mathrm{N}_{1}, \mathrm{~N}_{2}, \ldots \mathrm{N}_{\mathrm{n}}$ : São os números de dias da semeadura à primeira, segunda e última contagem, respectivamente.

O comprimento de planta $(\mathrm{CP})$ foi realizado após a colheita do Capim-Sudão, onde foi medido com régua graduada as plantas desde a base da inserção do caule na raiz até o ápice foliar.

O comprimento de raiz (CR) foi medido com régua graduada desde o ápice radicular até a base do caule do Capim-Sudão.

A massa verde da parte aérea (MVPA) e a massa verde da parte radicular (MVPR) foram feito com a pesagem em 
uma balança gravimétrica da parte aérea (caule, folhas) e na parte radicular (raízes) do Capim-Sudão logo após a colheita.

A massa seca da parte aérea (MSPA) e a massa seca da parte radicular (MSPR) foram secadas a parte aérea e prte radicular em estufa a $65^{\circ}$ durante 14 horas, e após foram pesados em balança gravimétrica obtendo a massa seca aérea e massa seca radicular do Capim- Sudão.

Para a obtenção da massa seca total (MST) do CapimSudão foi somado a massa seca da parte aérea mais a massa seca da parte radicular.

A relação raiz/parte aérea (R/PA) foi calculada, também no final do experimento, pelo quociente entre os valores de fitomassa seca de raízes e seca da parte aérea da planta, segundo a seguinte equação:

$$
R / P A=F S R / F S P A
$$

Em que: FSR: fitomassa seca do sistema radicular no final do experimento; FSPA: fitomassa seca da parte aérea no final do experimento.

A análise estatística do experimento foi utilizado o software (Sisvar) (FERREIRA, 2011).

\section{RESULTADOS E DISCUSSÃO}

Verifica-se através do resumo das analises estatística (Tabela 1) que a porcentagem de germinação $(\% \mathrm{G})$ foi significativa a 0,05 de probabilidade para extratos e doses, e não significativo na interação de extratos e doses apresentando coeficiente de variação de 19,56\%.

Quanto ao tipo de extrato a Aveia Preta e o Azevém não apresentaram diferença em análise estatística, sendo que apenas a mistura da Aveia Preta mais Azevém se diferenciou estatisticamente.

Nas doses de concentração as porcentagens de $0 \%$, $25 \%$ e $50 \%$ não diferenciaram estatisticamente, não houve efeito alelopático, enquanto nas porcentagens de $75 \%$ e $100 \%$ da dose se diferenciaram das demais apresentando efeito alelopático.

Segundo Meinerz et al., (2010), quanto ao número de sementes germinadas, para a alface foi observada menor germinação para as sementes submetidas ao teste de germinação com o extrato de aveia. Para demais tratamentos houve diferença significativa apenas nos dois primeiros dias, de forma que os extratos aquosos de azevém, braquiária e guandu mantiveram respectivamente, a germinação abaixo do controle testemunha (água destilada), não apresentado diferença estatística significativa após o terceiro dia de avaliação.

$O$ índice de velocidade de emergênc (IVE) a foi significativo a 0,05 de probabilidade para extratos e doses e não sendo significativo na interação de extrato e doses, com coeficiente de variação de 19,92\%.

A Aveia e o Azevém não se diferenciaram quanto ao tipo de extrato, havendo apenas diferenciação na mistura de Aveia + Azevém.

Tabela 1. Resumo da Anova e médias da percentagem de germinação (\%G), comprimento da planta (CP), comprimento da raiz (CR), raiz/parte área (R/PA) e índice de velocidade de emergência (IVE) em função do Extrato aquoso e das doses de concentrações do extrato.

\begin{tabular}{|c|c|c|c|c|c|c|}
\hline \multirow[t]{2}{*}{ Fonte de Variação } & \multicolumn{6}{|c|}{ Quadrados Médios } \\
\hline & GL & $\begin{array}{l}\% \mathrm{G} \# \\
(\%)\end{array}$ & $\begin{array}{l}\text { CP\# } \\
(\mathrm{cm})\end{array}$ & $\begin{array}{l}\text { CR\# } \\
(\mathrm{cm})\end{array}$ & $\begin{array}{l}\text { R/PA\#\#\# } \\
(\mathrm{g})\end{array}$ & IVE\#\# \\
\hline Extrato $(\mathrm{E})$ & 2 & $18,818 *$ & $8,864 *$ & $6,555^{*}$ & $0,001 \mathrm{~ns}$ & $0,473 *$ \\
\hline Doses (D) & 6 & $77,860 *$ & $34,342 *$ & $24,205^{*}$ & $0,0004 \mathrm{~ns}$ & $1,845^{*}$ \\
\hline Interação ExD & 4 & $0,001 \mathrm{~ns}$ & $0,001 \mathrm{~ns}$ & $0,001 \mathrm{~ns}$ & $0,002 \mathrm{~ns}$ & $0,001 \mathrm{~ns}$ \\
\hline Resíduo & 37 & 2,163 & 0,975 & 0,665 & 0,001 & 0,034 \\
\hline Total & 49 & - & - & - & - & - \\
\hline $\mathrm{CV} \%$ & - & 19,56 & 17,79 & 19,60 & 4,80 & 19,92 \\
\hline Tipo de Extrato & & & & Média & & \\
\hline Aveia Preta & & $56,50 \mathrm{~b}$ & $21,30 b$ & $17,19 b$ & 0,14 & $0,90 \mathrm{~b}$ \\
\hline Azevém & & $59,50 \mathrm{~b}$ & $22,32 b$ & $16,58 b$ & 0,12 & $0,93 b$ \\
\hline Aveia Preta + Azevém & & $85,00 \mathrm{a}$ & $33,67 \mathrm{a}$ & $26,22 \mathrm{a}$ & 0,13 & $1,45 \mathrm{a}$ \\
\hline Doses de Concentração (\%) & & $\%$ & $\mathrm{~cm}$ & $\mathrm{~cm}$ & $\mathrm{~cm}$ & $\mathrm{~cm}$ \\
\hline 0 & & $86,50 \mathrm{a}$ & $36,89 \mathrm{a}$ & $29,68 \mathrm{a}$ & 0,137 & $1,731 \mathrm{a}$ \\
\hline 25 & & $91,50 \mathrm{a}$ & $35,50 \mathrm{a}$ & $27,18 \mathrm{a}$ & 0,132 & $1,470 \mathrm{a}$ \\
\hline 50 & & $61,50 \mathrm{a}$ & $22,88 \mathrm{a}$ & $18,20 \mathrm{a}$ & 0,136 & $0,884 b$ \\
\hline 75 & & $26,50 b$ & $8,67 b$ & $8,21 b$ & 0,135 & $0,328 \mathrm{c}$ \\
\hline 100 & & $16,50 \mathrm{~b}$ & $2,54 \mathrm{~b}$ & $2,67 \mathrm{~b}$ & 0,116 & $0,158 \mathrm{c}$ \\
\hline
\end{tabular}

GL = grau de liberdade; $\mathrm{CV}=$ coeficiente de variação; $*=$ significativo a 0,05 de probabilidade; $* *=$ significativo a 0,01 de probabilidade; ns $=$ não significativo; \# Dados transformados em $\sqrt{x+1}$; \#\# Dados transformados em $\sqrt{x}$; \#\#\# Dados transformados em $\sqrt{x+0,5}$

As doses de concentração de $0 \%$ e $25 \%$ não diferenciaram estatisticamente apresentando maior velocidade de germinação, enquanto as doses de $50 \%$ se diferenciou das doses de $0 \%$ e $25 \%$ com velocidade de emergência mais lenta, já as porcentagens de $75 \%$ e $100 \%$ diferenciaram da dose de $50 \%$ apresentando velocidade de emergência mais lenta.

Segundo Ferreira e Áquila (2000) relatam que o efeito alelopático nem sempre é sobre o percentual de germinação, mas sobre a velocidade de germinação ou outra variável do processo germinativo, evidenciando a importância de um acompanhamento diário da germinação.

Entre extrato e doses foi significativo a 0,05 e probabilidade, e não significativo na interação extratos e doses, apresentando coeficiente de variação de 17,79\%.

O extrato de Aveia e o Azevém não apresentaram diferença entre elas, porém diferenciaram da mistura de Aveia +Azevém quanto ao tipo de extrato. 
Para as doses de concentração $0 \%, 25 \%$ e $50 \%$ não houve diferenciação no comprimento de plantas, mas nas doses de $75 \%$ e $100 \%$ diferenciaram das demais dosagens apresentando comprimento de plantas menor.

Foi significativo a 0,05 de probabilidade para extratos e doses, e não significativo na interação de extratos e doses e com coeficiente de variação de $19,60 \%$.

Com relação ao tipo de extrato a Aveia e o Azevém não diferenciaram, mas em relação a mistura dos extratos Aveia + Azevém teve diferenciação.

Em dose de concentração $0 \%, 25 \%$ e $50 \%$ não diferenciou o comprimento de raiz, mas em doses de $75 \%$ e $100 \%$ as raízes obtiveram tamanho reduzido.

Para Silveira et al. (2012), quanto ao comprimento de raiz e comprimento da parte aérea observa-se que todos os extratos afetaram negativamente o crescimento, reduzindo o comprimento da raiz em mais de 50\%. Quanto maior a concentração dos extratos, menor foi o comprimento de raiz e comprimento da parte aérea da alface.
Pelo resumo das análises de variância (Tabela 2) para extratos e doses apresentaram efeito significativo a 0,05 de probabilidade, porém, na interação extratos e doses $\left(E^{*} \mathrm{D}\right)$, não significativo e com coeficiente de variação de $25,19 \%$.

Em relação ao tipo de extrato a Aveia e o Azevém não se diferenciaram, entretanto, Aveia + Azevém diferenciou dos demais tratamentos.

Para as fontes de variação extrato e doses foi significativo a 0,05 de probabilidade, e não significativo na interação extrato e doses, e com coeficiente de variação $24,90 \%$. E para o tipo de extrato a Aveia e o Azevém não diferenciaram, mas a Aveia + Azevém diferenciou das demais.

$\mathrm{O}$ extrato e as doses mantiveram significativos a $0,05 \mathrm{de}$ probabilidade e não significativo na interação de extratos e doses, e com coeficiente de variação de $28,63 \%$.

No tipo de extrato a Aveia e o Azevém não diferenciaram, mas se diferenciaram quanto à mistura das doses de Aveia + Azevém.

Tabela 2. Resumo da Anova e médias de massa fresca da parte área (MVPA), massa seca da parte área (MSPA), massa fresca da raiz (MVPR), massa seca da raiz (MSPR) e massa seca total (MST) em função do Extrato aquoso e das doses de concentrações do extrato.

\begin{tabular}{|c|c|c|c|c|c|c|}
\hline \multirow[t]{2}{*}{ Fonte de Variação } & \multicolumn{6}{|c|}{ Quadrados Médios } \\
\hline & GL & $\begin{array}{l}\text { MVPA\#\# } \\
\text { (g) }\end{array}$ & $\begin{array}{l}\text { MSPA\#\# } \\
(\mathrm{g})\end{array}$ & $\begin{array}{l}\text { MVPR\#\# } \\
(\mathrm{g})\end{array}$ & $\begin{array}{l}\text { MSPR\#\# } \\
(\mathrm{g})\end{array}$ & $\begin{array}{l}\text { MST\#\# } \\
(\mathrm{g})\end{array}$ \\
\hline Extrato $(\mathrm{E})$ & 2 & $0,465^{*}$ & $0,051 *$ & $0,052 *$ & $0,024 *$ & $0,076^{*}$ \\
\hline Doses (D) & 6 & $1,810^{*}$ & $0,277 *$ & $0,238 *$ & $0,114 *$ & $0,391 *$ \\
\hline Interação ExD & 4 & $0,001 \mathrm{~ns}$ & $0,001 \mathrm{~ns}$ & $0,001 \mathrm{~ns}$ & $0,001 \mathrm{~ns}$ & $0,001 \mathrm{~ns}$ \\
\hline Resíduo & 37 & 0,042 & 0,007 & 0,007 & 0,002 & 0,009 \\
\hline Total & 49 & - & - & - & - & - \\
\hline $\mathrm{CV} \%$ & - & 25,19 & 24,90 & 28,63 & 23,07 & 23,59 \\
\hline Tipo de Extrato & \multicolumn{6}{|c|}{ Média } \\
\hline Aveia Preta & & $0,73 b$ & $0,13 b$ & $0,10 \mathrm{~b}$ & $0,05 b$ & $0,18 \mathrm{~b}$ \\
\hline Azevém & & $0,75 b$ & $0,13 b$ & $0,10 \mathrm{~b}$ & $0,05 b$ & $0,18 b$ \\
\hline Aveia Preta + Azevém & & $1,21^{\mathrm{a}}$ & $0,18^{\mathrm{a}}$ & $0,16 \mathrm{a}$ & $0,08 \mathrm{a}$ & $0,26 a$ \\
\hline Doses de Concentração (\%) & & $\mathrm{cm}$ & $\mathrm{cm}$ & $\mathrm{cm}$ & $\mathrm{cm}$ & $\mathrm{cm}$ \\
\hline 0 & & $1,472 \mathrm{a}$ & $0,227 \mathrm{a}$ & $0,202 \mathrm{a}$ & $0,098 \mathrm{a}$ & $0,325 \mathrm{a}$ \\
\hline 25 & & $1,182 \mathrm{ab}$ & $0,210 \mathrm{ab}$ & $0159 a$ & $0,077 \mathrm{~b}$ & $0,286 \mathrm{ab}$ \\
\hline 50 & & $0,722 b c$ & $0,127 b c$ & $0,096 \mathrm{ab}$ & $0,045 b$ & $0,172 b$ \\
\hline 75 & & $0,285 \mathrm{~cd}$ & $0,043 \mathrm{~d}$ & $0,037 \mathrm{bc}$ & $0,016 \mathrm{c}$ & $0,059 \mathrm{c}$ \\
\hline 100 & & $0,069 \mathrm{~d}$ & $0,020 \mathrm{~d}$ & $0,010 \mathrm{c}$ & $0,007 \mathrm{c}$ & $0,027 \mathrm{c}$ \\
\hline
\end{tabular}

$\overline{\mathrm{GL}}=$ grau de liberdade; $\mathrm{CV}=$ coeficiente de variação; *= significativo a 0,05 de probabilidade; $* *=$ significativo a 0,01 de probabilidade; ns $=$ não significativo; \# Dados transformados em $\sqrt{x+1}$; \#\# Dados transformados em $\sqrt{x}$; \#\#\# Dados transformados em $\sqrt{x+0,5}$.

Para Veronka (2011), quanto ao peso fresco da raiz seminal e da parte aérea, os maiores valores foram encontrados no teste controle, para as três cultivares. $\grave{A}$ medida que a dose de ExD70 aumentou a biomassa fresca diminuiu, chegando até a total inibição do crescimento das mesmas.

Nas fontes de variação extrato e doses foram significativos a 0,05 de probabilidade, e não significativos na interação extrato e doses, apresentando coeficiente de variação de $23,07 \%$.

Nos tipos de extrato Aveia e Azevém não variaram, sendo apenas a mistura de Aveia + Azevém que houve variação.

Nas doses de concentração $0 \%$ diferenciou da dose $25 \%$, e as doses de $25 \%$ e $50 \%$ não diferenciaram entre si, que também não variou foi nas doses de $75 \%$ e $100 \%$ que se diferenciaram da dose de $50 \%$.
Conforme menciona Veronka (2011), que para as cultivares testadas, com o aumento da concentração do extrato, houve redução da biomassa seca da raiz seminal e da parte aérea.

A fonte de variação extrato e doses foram significativas a 0,05 de probabilidade, mas a interação extrato e doses não foi significativo, apresentando coeficiente de variação de $23,59 \%$.

E nos tipos de doses a Aveia e Azevém não diferenciaram, apenas diferenciando na mistura das doses de Aveia + Azevém.

Nas doses de concentração $0 \%$ não se diferenciou da dose de $25 \%$, mas as dose de $25 \%$ e $50 \%$ também não diferenciaram, apenas a dose de $50 \%$ diferencio da dose de $0 \%$, e as doses de $75 \%$ e $100 \%$ não variaram entre si, mas diferenciando das demais.

Segundo Veronka (2011), a produção de biomassa total foi afetada pelo ExD70. A biomassa foi 
significativamente maior $(\mathrm{P}<0,5)$ no teste controle, e quanto maior a dose do extrato menor foi o volume de biomassa total.

Não foi significativa para a fonte de variação extrato e doses, e nem para a interação das mesmas, apresentando coeficiente de variação de $4,80 \%$.

E quanto ao tipo de extrato usado e as dosagens não houve variações.

\section{CONCLUSÕES}

Nas variáveis porcentagem de germinação, comprimento de plantas e comprimento de raízes comparadas nas dosagens do extrato aquoso houve efeito alelopático na germinação do Capim-Sudão. Mas nas dosagens de $75 \%$ e $100 \%$ foram as que obtiveram maiores resultados alelopático, e quanto ao tipo de extrato, a mistura da Aveia + Azevém se destacou dos demais tipos Aveia e Azevém.

E pelos índices de massa fresca e seca da parte aérea e radicular, e também visto no índice de velocidade de germinação que a partir das doses de $50 \%$ da solução aquosa dos extratos da Aveia e Azevém e da mistura Aveia + Azevém que ocorreram efeito alelopático sobre a germinação do Capim-Sudão.

Sugere realizar mais estudos a respeito dos efeitos aleloquímicos realizando diferentes épocas de dessecação a campo da Aveia e Azevém para ver como se comporta o desenvolvimento do Capim-Sudão.

\section{REFERÊNCIAS}

ABBADO, M. R. Estabelecimento de capim elefante (Pennistum purpureum Schum) em áreas de Brachiaria decumbens Stapf. explorando o potencial alelopático de leguminosas tropicais. 1995. 83 p. Dissertação (Mestrado em Ciência Animal e Pastagens) - Escola Superior de Agricultura "Luiz Queiroz", Piracicaba.

ALMEIDA, A. R. P. Efeito alelopático de espécies de Brachiaria Griseb. sobre algumas leguminosas forrageiras tropicais. 1993. 73 p. Dissertação (Mestrado em Fisiologia e Bioquímica de Plantas) - Escola Superior de Agricultura "Luiz Queiroz", Piracicaba.

ALVES, M. C. S.; FILHO, S. M.; INNECCO, R.; TORRES, S.B. Alelopatia de extratos voláteis na germinação de sementes e no comprimento da raiz de alface. Pesquisa Agropecuária Brasileira, Brasília, v.39, n.11, p.1083-1086, 2004.

BENINCASA, M. M. P. Análise de crescimento de plantas: noções básicas. Jaboticabal: FUNEP, 2003. $41 \mathrm{p}$.

CECATO, U.; SARTI, L. L.; SAKAGUTI, E. S.; DAMASCENO, J. C.; REZENDE, R.; SANTOS, G. T. Avaliação de cultivares e linhagens de Aveia (Avenna spp.). Acta Scientiarum, Maringá, v. 20, n. 3, p. 347-354. 1998.

FERREIRA, D. F. SISVAR: um programa para análises e ensino de estatística. Revista Symposium, v.6, p.36-41, 2011.
FERREIRA, A. G; AQUILA, M. E. A. Alelopatia: uma área emergente da ecofisiologia. Revista Brasileira de Fisiologia Vegetal, Campinas, v.12, p.175-204, 2000. Volume especial.

FERREIRA, A. G.; BORGUETTI, F. Interferência: Competição e Alelopatia. In: FERREIRA, A. G., BORGUETTI, F. Germinação: do básico ao aplicado. Porto Alegre: Ed. Artmed, 2004, p.252-262.

FONSECA, D. M. da; MARTUSCELLO, J. A. Plantas Forrageiras. Viçosa, MG. Ed UFV. 537p. 2010.

GOOOGLE EARTH. MAPAS. http://mapas.google.com. Consulta realizada em 02. Fev. 2008.

MEINERZ, C. C.; MÜLLER, S. F.; CASTAGNARA, D. D. UNIOESTE; HARTSMM-SCHIMIT, M. A. UNIOESTE; MARTINAZZO-POTZ, T.; GUIMARÃES, V. F.; Efeito alelopático de plantas de cobertura na germinação de sementes de alface; Resumos do III Seminário de Agroecologia de MS; Cadernos de Agroecologia, Vol 5 N.1, 2010.

NERY, M. C.; CARVALHO, M. L. M.; NERY, F. C.; PIRES, R. M. de O. Potencial alelopático de Raphanus sativus $L$. var. oleiferus. Informativo ABRATES, v. 23, n. 1 p. 15-20, 2013. Disponível em: http://www.abrates.org.br/portal/images/Informativo/v23_n1/ 01._Raquel_Alelopatia.pdf. Acesso em: 06 jul. 2013.

RAMON, J., Pastagens de Verão, Relatório de Inteligência Analítico, Florianópolis - SC, SEBRAE, 2012, p. 13.

RICE, E. L. Allelopathy. New York: Academic Press,1984, $422 \mathrm{p}$.

ROSO, C.; RESTLE, J.. Aveia preta, triticale e centeio em misturas com azevém - Produtividade animal e retorno econômico;Revista Brasileira de Zootecnia, v.29 n.1 Viçosa, MG, 2000.

SANTA CATARINA, Secretaria do Estado de Desenvolvimento Regional -Lages - SDR. Proposta de criação da área de preservação ambiental Coxilha Rica. Lages: Instituto Coxilha Rica, 2007. 408 p

SILVA, Z. L. Alelopatia e defesa em plantas. Boletim Geográfico, Rio de Janeiro, v. 36, n. 258-259, 1978.

SILVEIRA, P. F. Efeito alelopático do extrato aquoso dejurema-preta (mimosa tenuiflora(willd.) Poir.) Sobre a germinação de ementes de alface (lactuca satival). 2010. 48 p. Dissertação (Mestrado em Fitotecnia) - Universidade Federal do Semi-Árido-UFERSA, Mossoró/RN..

SILVEIRA, P. F.; MAIA, S. S. S.; COELHO, M. F. B.; Potencial alelopático do extrato aquoso de folhas de mimosa tenuiflora (willd.) poir. na germinação de lactuca sativa 1.; Biosci. J., Uberlândia, v. 28, n. 3, p. 472-477, May/June. 2012. 
SMITH, A. E., MARTIN, D. L. Allelopathic characteristics of three coop-season grass in the forage ecosystems. Agronomy Journal, v.8, n.2, p.243-246, 1994.

SOUZA, L. S.; VELINI, E. D.; MAIOMI-RODELLA, R. C. S. Avaliação do efeito alelopatico de 18 espécies de plantas daninhas sobre o crescimento inicial de Eucalyptus grandis. In: CONGRESSO BRASILEIRO DE HERBICIDAS E PLANTAS DANINHAS, 19., 1993, Londrina. Resumos... Londrina: [s.n], 1993.

VERONKA, D. A. Alelopatia do extrato bruto de brachiaria decumbens na germinação de sementes e no vigor de sementes e de plântulas de brachiaria brizantha. Universidade Anhanguera - uniderp. Programa de mestrado profissional em produção e gestão agroindustrial, Campo Grande - MS, 2011.

VITOR, C. M. T., FONSECA, D. M., CÓSER, A. C., MARTINS, C. E., NASCIMENTO JÚNIOR, D.; RIBEIRO JÚNIOR, J. I. Produção de matéria seca e valor nutritivo de pastagem de capim-elefante sob irrigação e adubação nitrogenada. Rev Bras Zootecn, 38: 435-442. 2009.

ZAGO, C. P. Utilização do sorgo na alimentação de ruminantes. Sete Lagoas: EMBRAPA - Centro Nacional de Pesquisas de Milho e Sorgo, 1997. p.9-25. 